\title{
Taita Taveta university college e-voting system: a web based approach to elections management
}

\author{
J. M. Nzoka, N. M. Muthama, N. M. Mung'ithya \\ Department of Mathematics and Informatics of Taita Taveta University College, Voi, Kenya, P.O.BOX 635-80300, Voi-Kenya
}

Email address:

joshua.jkuat@gmail.com(J. M. Nzoka),nicholasmuthama@ttuc.ac.ke(N. M. Muthama),nmutua2@gmail.com(N. M. Mung’ithya)

\section{To cite this article:}

J. M. Nzoka, N. M. Muthama, N. M. Mung'ithya. Taita Taveta University College E-Voting System: A Web Based Approach to Elections Management. International Journal of Intelligent Information Systems. Vol. 2, No. 5, 2013, pp. 70-76. doi: 10.11648/j.ijiis.20130205.11

\begin{abstract}
Most institutions of higher learning such as universities and colleges world over provide for an electioneering process where students elect their union leaders in a democratic manner. This is of great importance as it inculcates the principle of democracy into the students who are at the peak of their learning stage and would need these skills for better statesmanship. Proper management therefore is called for to provide foolproof processes which can be termed as free and fair in the standards of universal democracy and employment of Information Technology is a sure way to realize this. Online voting is the application of web based technologies to the automation of voting processes. In online voting a voter cast their ballot from a remote terminal that is connected to the central database where actual processing of the ballot is done. Online systems have the advantage of providing convenience to the voter and reduce the time wasted in the queuing process at election centers. This paper describes a research carried out at Taita Taveta University College, a higher learning institution in Kenya and the process undertaken to achieve development and deployment of a web based system to promote free and fair democratic electioneering process: computerizing registration, voting and tallying process involved. The system described is in form of a portal that is embedded on the Universities website. The system was developed using the incremental prototyping due to the adaptive nature of web based applications and the system proved that a computerized solution is possible with elimination of human related faults that are a commonplace in employment of human clerks to manage the election process. Integration with SMS functionalities helped increase safety and reliability of the system. Application of the online voting has resulted in many advantages in the efficiency of the entire electioneering process and reduced costs the university used to incur using the human clerk mechanism.
\end{abstract}

Keywords: E-Voting, Election Management System, Web Based Voting, Foolproof, Web Technologies, Portal, Prototyping, Faults

\section{Introduction}

Elections form a critical process in democratic systems and application of information technologies to their management is a great milestone towards realizing effectiveness and efficiency not only in the results of the election process itself but also in the financial implications that come up with the process.

At Taita Taveta University College, one of the public institutes of higher learning in Kenya, computerized management of student union elections was called for due to the shortcomings in the 'human clerk 'electioneering system.

As a result no special date could be fixed to accommodate all the students. Moreover the traditional voting system could not be counted upon given the drawbacks in terms of collusion between the electronic officials and contestants, the queuing time, delayed results, overworked tallying officials and the undeniable fact of human errors. The existing voting system did not provide reliable statistics on voting history in the college and thus campaigners lacked the ground to apply scientific voter forecasting methods resolving to trial and error methodologies which are error prone and inconsistent.

Reinforcing a one voter one vote policy is difficult in such a situation and malpractices as rigging are not uncommon in human clerk system.

The traditional human clerk mechanisms employed in the management of electioneering procedures at Taita Taveta University College were not foolproof and were prone to inconsistencies, election malpractices and untimely delivery of results leading to questions at to the 
credibility and validity of the results the returning officer announces. Much expense was in incurred in the production, transportation, storage and destruction of the ballot papers and ballot boxes. Therefore research project was carried with the following primary objectives

i. To investigate user requirements for a web based voting portal

ii. To provide a portal via which students of Taita Taveta University College can cast their votes online

iii. To provide a system that automatically tallies cast votes for individual candidates

iv. To provide a system that archives summarized reports and statistics with regard to the conduct of an election process

v. To provide management and administration of Taita Taveta University College an easy way to manage and monitor the entire election process from a computer based interface.

vi. To provide a ground for further research into this field and enrich the academia.

\section{Literature Review}

Ballot voting is a democratic process whereby a group of individuals expresses its opinion and choice by way of casting a ballot. The ballot process involves presenting a voter with a list of choices to mark against their favorite choice. Ballot mechanism has been in existent since 139 BC [Wikipedia.2013.] as practiced by ancient Romans. Indians adopted ballot mechanism at around $920 \mathrm{AD}$. Variations of the ballot mechanism comprised of scratching the names of choice candidates on pieces of broken pottery [Greece] and use of Palm leaves with names of candidates, a practice known as Kudavolai in India. United States was to employ ballot papers in 1629 to select a pastor for the Salem Church [ballotpedia.2013.].

With onset of technology and computers, computerized processes have been invented world over to improve efficiency and credibility of voting processes. Two distinct approaches in computerized voting processes are electronic voting and online voting. While online voting aims to provide a web based interface via which voters can cast their votes and get results of the election process, electronic voting has to do with the registration process being carried out electronically e.g. use of biometrics and coded voter cards that that can be scanned by an electronic device to authenticate the voter. Thus, an electronic voting system may end up having human clerks tallying the votes upon termination of the election process.

Canada and Estonia are among the pioneers of online voting, CNN, Why Can't America Vote Online, [November 8 , 2011] with the town of Markham, in Ontario, having offered online ballots in local elections since 2003.

David Chaum advocates for a scheme [5], whereby voters could get receipts for their votes. This receipt would allow them to verify whether their votes were included in the final tally or not, and to prove that they voted without revealing any information about how they voted. The inclusion of this improves credibility in the election process.

David Chaum [vote2012] suggests that e-voting is technologically viable with application of cryptography and security reinforcement algorithms.

Matt Schultz and Tom Miller [2012] protested that database matching in online voting processes had loopholes as illegal voters managed to get registered. This is a challenge that comes when a system provides online registration and should be well addressed to ensure such incidences never occur. The duo proposes a personal identity number to uniquely identify each voter and facilitate cross checking. Their insight was therefore of great aide in the design considerations of the system.

Dr. Michael Shamos of CMU provides a sharp counterpoint [6] to Neumann and

Mercuri's views. He presents Six Commandments summary of requirements for a voting which though similar to others' requirements, he maintains himself as less afraid of the catastrophic failures and sweeping fraud made possible by imperfections in electronic voting machines. Shamos is also much less impressed with paper ballots than are Neumann and Mercuri. He places a great deal of faith in decentralization to make fraud difficult to commit and easy to detect.

V. Kalaichelviand R.M. Chandrasekaran [2] suggest online voting as a solution to curb the challenge of cheating in elections and provide a baseline for online voting system as that such a system should provide a high level of security and establish five core requirements of an electronic voting system to address issues of privacy, authentication, anonymous, uniqueness and coercion.

University of Texas [A\&M University] online voting system shows that web technologies can be harnessed to facilitate voting processes and one no longer needs to be physically at the Campus setting to exercise their democratic right as a student. The system exposes a web interface via which students log in and cast their votes during the electioneering period. In Kenya, universities and colleges have to rely on the human clerk electoral processes.

\section{Case Study}

The research design adopted for the project was case study method formulated in Lanmek, 2005 as "The case study is an approach, situated between concrete data taking techniques and methodological paradigms".

\subsection{Problem Statement}

The college has an overall enrolment to the tune of 2000 students enrolled in the diverse fields of study. Student Union elections within the college had been faced with many challenges given variations in reporting time and academic year cycles as leading the list of challenges. This made fixing a specific date for elections a challenge as no single semester would suit all the students. Moreover the 
traditional 'human clerk' mechanism could not be counted upon given the drawbacks in terms of collusion between electoral officials and the contestants, the queuing time, delayed results, overworked officials and the undeniable aspect of human error. The existing system did not provide reliable statistics on voting history within the colleges and campaigners lacked the ground to apply scientific voter forecasting methods resolving to trial and error methodologies which are error prone and inconsistent. Reinforcing a one voter one vote policy is difficult in such a situation and malpractices as rigging are not uncommon in human clerk system.

In the light of the afore-stated challenges it was deemed necessary to come up with a system that addresses them and ensures that students vote at their comfort: wherever and whenever, control paper wastage and provide credible tallying and tabulation of votes.

\subsection{Project management Methodology}

The development methodology adopted for the system was incremental prototyping due to its provision of quick feedback between users and the developer in between the development period as the users are able to test the developed components and their functionality.

Project scheduling was done using Project Evaluation and Review Technique.

\begin{tabular}{|c|c|c|c|c|c|}
\hline 1/10/2012 & 1 day & 1/10/201 & 2/10/2012 & 7 days & $8 / 10 / 2012$ \\
\hline \multicolumn{3}{|c|}{ Problem Identifiacation } & \multicolumn{3}{|c|}{ Feasibility analysis } \\
\hline $1 / 10 / 2012$ & Odays & 1/10/2013 & 2/10/2012 & 0 days & 8/10/2012 \\
\hline & & & 9102012 & 5 days & 13/10/20/12 \\
\hline & & & \multicolumn{3}{|c|}{ Requirements Gathering } \\
\hline & & & 8/10/2012 & 0 & 13/10/2012 \\
\hline & & & \multicolumn{3}{|c|}{$\downarrow$} \\
\hline 19/10/2012 & 14 days & 2/11/2012 & 14/10/2012 & 5 & 18/10/2012 \\
\hline \multicolumn{3}{|c|}{ Specifcation design } & \multicolumn{3}{|c|}{ Requirements analysis } \\
\hline 20/10/2012 & 0 & 3/11/2012 & 14/10/2012 & 0 & 18/10/2012 \\
\hline 3/11/2012 & 14 days & 18/11/2012 & 17/11/201 & $2 \mathrm{dz}$ & $18 / 11 / 2012$ \\
\hline & Coding & & & Test: & \\
\hline 4/11/2012 & 0 & 17/11/2012 & 18/11/201 & 0 & 18/11/2012 \\
\hline
\end{tabular}

Figure 1. Pert chart

\subsection{Conceptual Design}

The conceptual development of the system was done using use case diagrams and system flowcharts which are as illustrated below.

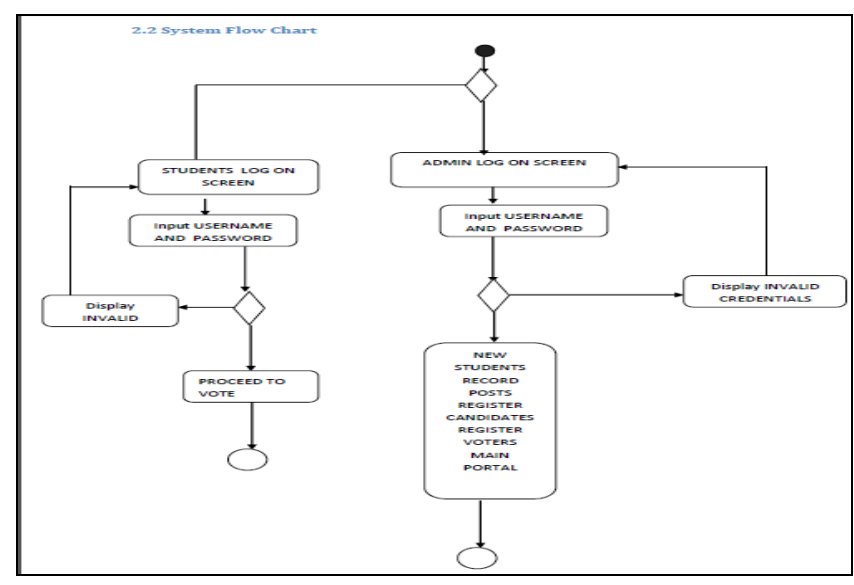

Figure 2. System Flowchart

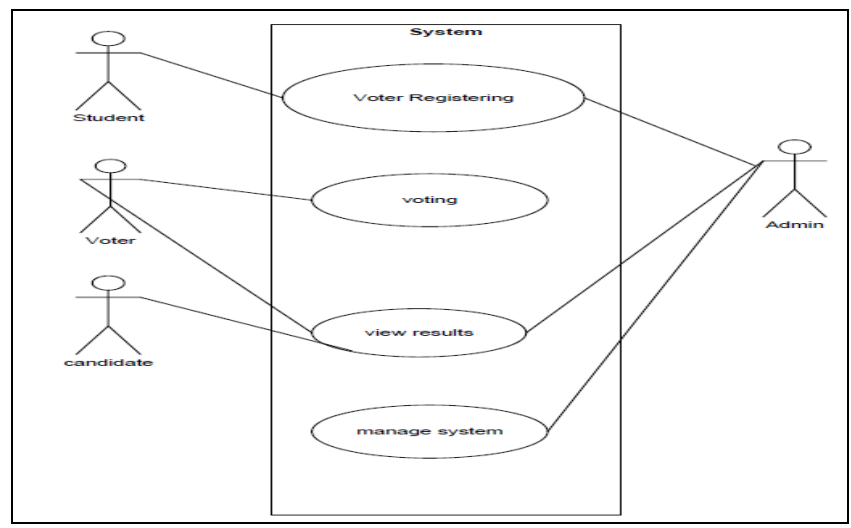

Figure 3. System Use Case Diagram

\subsection{Physical Design}

Table1. Data Dictionary

\begin{tabular}{lllll}
\hline Field & Type & Null & Default Comments & MIME \\
\hline username & text & No & \\
password & text & No & \\
\hline
\end{tabular}

Table2. Candidates

\begin{tabular}{|c|c|c|c|c|}
\hline Field & Type & Null & Default & Comments MIME \\
\hline reg_num & text & No & & \\
\hline post & text & No & & \\
\hline votes & $\operatorname{int}(11)$ & No & & \\
\hline electionyeare & text & No & & \\
\hline \multicolumn{5}{|c|}{ Table3. Department } \\
\hline Field & Type & Null & Default & Comments MIME \\
\hline$\underline{\mathrm{id}}$ & $\operatorname{int}(11)$ & No & & \\
\hline dept_name & text & No & & \\
\hline abbreviation & text & No & & \\
\hline dept_chair & text & No & & \\
\hline
\end{tabular}


Table4. Electionyear

\begin{tabular}{|c|c|c|c|c|}
\hline Field & Type & Null & Default & Comments MIME \\
\hline year & year(4) & No & & \\
\hline flag & tinyint(1) & No & & \\
\hline voteFlag & tinyint(1) & No & & \\
\hline currentPointer & tinyint(1) & No & & \\
\hline
\end{tabular}

Table5. Hostel

\begin{tabular}{|c|c|c|c|c|}
\hline Field & Type & Null & Default & Comments MIME \\
\hline hostelname & text & No & & \\
\hline category & text & No & & \\
\hline$\underline{\mathrm{id}}$ & $\operatorname{int}(11)$ & No & & \\
\hline Description & text & No & & \\
\hline
\end{tabular}

Table6. Names

\begin{tabular}{|c|c|c|c|c|c|}
\hline Field & Type & Null & Default & Comments & MIME \\
\hline id & text & No & & & \\
\hline First & text & No & & & \\
\hline $\mathrm{sec}$ & text & No & & & \\
\hline
\end{tabular}

Table7. Posts

\begin{tabular}{|c|c|c|c|c|}
\hline Field & Type & Null & Default & Comments MIME \\
\hline title & text & No & & \\
\hline abbreviation & text & No & & \\
\hline spoiltvotes & $\operatorname{int}(11)$ & No & & \\
\hline
\end{tabular}

Table8. Sess

\begin{tabular}{|c|c|c|c|c|}
\hline Field & Type & Null & Default & Comments MIME \\
\hline$\underline{\mathrm{id}}$ & $\operatorname{int}(11)$ & No & & \\
\hline code & $\operatorname{varchar}(100)$ & No & & \\
\hline user_id & varchar(100) & No & & \\
\hline
\end{tabular}

Table9. Students

\begin{tabular}{|c|c|c|c|c|c|}
\hline Field & Type & Null & Default & Comments & MME \\
\hline$\underline{\mathrm{id}}$ & $\operatorname{int}(11)$ & No & & Autocrement number & \\
\hline reg_num & text & No & & & \\
\hline first_name & text & No & & & \\
\hline last_name & text & No & & & \\
\hline gender & text & No & & & \\
\hline year_adm & text & No & & & \\
\hline department & text & No & & & \\
\hline hostel & text & No & & & \\
\hline
\end{tabular}

Table10. Voted

\begin{tabular}{|c|c|c|c|c|}
\hline Field & Type & Null & Default & Comments MIME \\
\hline$\underline{\mathrm{id}}$ & $\operatorname{int}(11)$ & No & & \\
\hline reg_num & text & No & & \\
\hline time_voted & text & No & & \\
\hline
\end{tabular}

Table11. Voters

\begin{tabular}{|c|c|c|c|c|}
\hline Field & Type & Null & Default & Comments MIME \\
\hline reg_num & text & No & & \\
\hline code & text & No & & \\
\hline email & text & No & & \\
\hline mobile & text & No & & \\
\hline electionyear & text & No & & \\
\hline
\end{tabular}

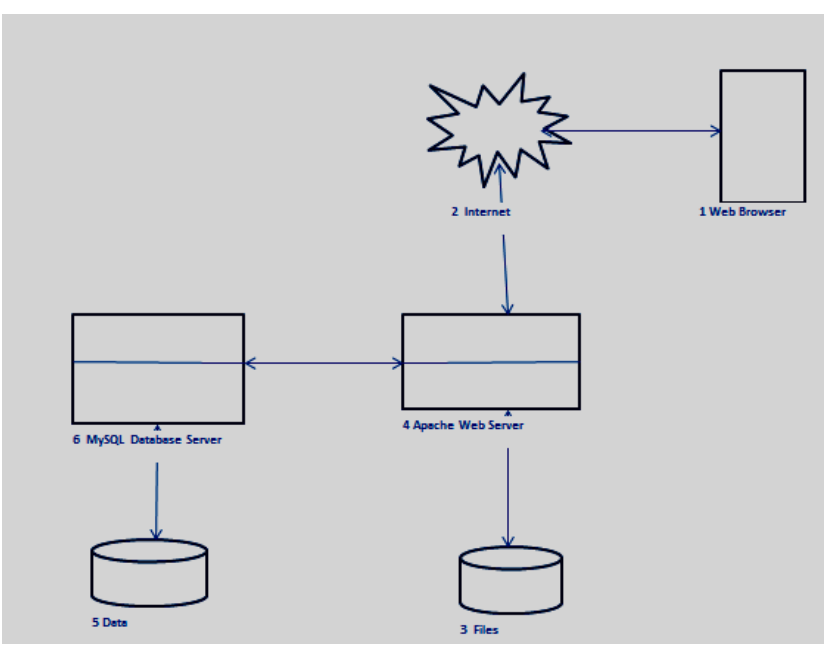

Figure 4. System Architecture

\subsection{Implementation}

The system was implemented using PHP and MySQL server technologies. The client side was done in DHTML set of technologies.

The system requires the following as the basic requirements:

\section{Hardware}

512 MB RAM 50 GB HDD, $1.5 \mathrm{GHz}$

\section{Software}

Windows Xp

Apache Server

\subsection{System Testing}

\subsubsection{Objectives of testing}

i. To establish that the software worked satisfactorily as per the requirements

ii. To prove that the program is error free

iii. To certify that the software functioned correctly and could be used in production

\subsubsection{Testing Process}

The software testing team comprising of the lead ICT management of Taita Taveta University College conducted both white box testing and black box testing on the system before deployment. The system was approved for deployment by the testing team having satisfied the testing objectives. 


\subsection{System Deployment}

The following steps were followed to deploy the system after testing and acceptance by the organization

i. Subdomain creation

A subdomain was created to host the webpages and all other files as images, the cascading style sheet files and javascript files.

i. Database importing

Using the hosting account, the database file was imported from the localhost (hosting environment) of the testing server.

Address: www.portal.skyspringinternational.co.ke

\subsection{System Maintenance}

The system maintenance is divided into the four main sections of maintenance as will be routinely carried out in the lifecycle of the system. Maintenance will be carried out at intervals of four months to ensure smooth running of the system.

\subsubsection{Corrective Maintenance}

Corrective maintenance involves those activities dedicated to fix potential bugs not initially detected and foreseen by the designers and will involve

i. Having a help desk assistant to assist in error report logging as will be reported by users of the system

ii. A provision for notifying the development team of the error to have the error fixed

iii. Testing fixes of bugs and their impacts

\subsubsection{Adaptive Maintenance}

Changes in the organization will impact on the system and call for maintenance activities. Such activities that fall under adaptive maintenance are:-

i. reorganizing and restructuring the database to reflect new admission criteria

ii. addition of new tables in the database

iii. adding new web pages that reflect added functionalities

iv. integrating new technologies as biometrics in the system

\subsubsection{Perfective Maintenance}

This will be necessitated by the organization's desire to improve and realize more functionality from the system and will involve tasks as

i. Upgrading from one web hosting server to another

ii. Upgrading web hosting account

iii. Adding more functionalities

\subsubsection{Preventive Maintenance}

Periodic performance benchmarking will be done once every three months to ensure the system continues to operate as expected.

Such tasks will be

i. Monitoring and fixation of bugs

ii. Monitoring and fixing of blind and broken links

\section{Lessons Learned}

Taita Taveta University E-Voting System completely meets the objectives for its development such as

i. To provide a portal via which students of Taita Taveta University College can cast their votes online

The students of Taita Taveta University have a safe and reliable portal through which they can cast their votes at their convenience regardless of the their location

ii. To provide a system that automatically tallies cast votes for individual candidates

The tallying process is done by the system which outputs summarized data regarding a particular criterion of interests e.g. how much votes are cast for a candidate or which candidate emerged winner in specific contested post.

iii. To provide a system that archives summarized reports and statistics with regard to the conduct of an election process

The computerized database serves as warehouse hosting records of data pertaining election processes in the University and application of data mining principles can assist campaigners in their strategy formulation.

iv. To provide management and administration of Taita Taveta University College an easy way to manage and monitor the entire election process from a computer based interface.

The administration of Taita Taveta can now monitor the process of election with more ease than never before in the era of human clerk system and there is a report of reduced paper wastage.

\section{Recommendation}

Social Institutions which have democratic processes should embrace web technologies to manage their electioneering processes as this will improve their effectiveness of rendering such processes and save them huge costs and time. The application of web based approaches in solving electioneering processes should be applied even in managing national elections in developing countries. Moreover, with the advancement in technologies, biometric measures such as face and finger print recognition algorithms could be applied to enhance security and improve credibility of online voting systems.

\section{Conclusion}

Web based portals provide a great opportunity to organizations, institutions and geographical entities as counties and countries which can be harnessed to promote free and fair elections. The system presented in this article provides a solution to many problems prevalent in democratic processes and can be extended to national politics level by countries in the developing world with some modification. 


\section{Acknowledgements}

This work was accomplished through support and contributions from a number of individuals. The students of Taita Taveta University College, and more so those from the Mathematics and Informatics department, thank you for your input in evaluation of user requirements for the system. Special thanks to the Department of ICT in Taita Taveta University College for the material support towards the success of the research project.

\section{Appendixes}

\section{Appendix A: Screen of Main Portal}

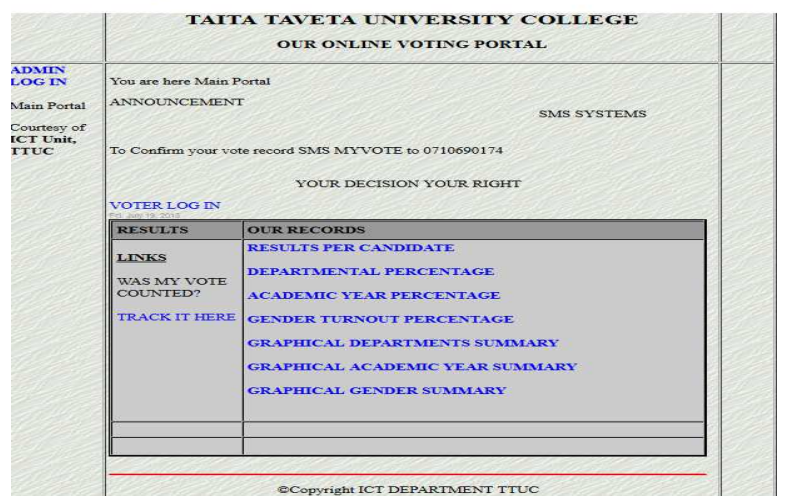

\section{Appendix B: User Guides}

This is a guide for the routine operations of the system

\section{Administrator Module}

\section{Administrator log in}

1. Use the link admin log in from the main portal

2. Enter administrator username and password.

3. Note the system currently provides for one administrator account.

4. Click submit to log in to your admin panel

\section{Administrator's Panel}

1. Add new student

Use the New Student link to open new record form

2. Add new Voter

Use the link Record Voters to register a student as a voter.

3. Adding new Candidate

Use the link Record Candidates to register a student as a candidate contesting for an elective post

4. Adding new post

Use the link Record Posts to add new posts to be contested for

5. Flagging on and off

Use the select year drop down and click flag or $\mathrm{u}$ flag to toggle between true or false states of voting or election flags.

Note voting flag is can only be set true for the current year only.

\section{Voter Module}

\section{Voter log in}

1. Use the link voter log in on the main portal

2. Enter your registration number as the username

3. Enter the secret code sent to you via SMS during registration as the password

Voter's Portal

\section{Voting}

1. Select the preferred candidates on the drop down lists for each of the post.

2. Click the submit button to cast your vote

\section{Confirming your vote status}

Use the link "confirm vote" on the main portal

1. Use the link Vote Confirmation link on the main portal

2. Enter username and password (secret code)

3. Click submit

4. You will be presented with a certificate with your voting details.

\section{General Users}

\section{Statistics}

The main portal has updated statistics for the current year on

1. Voter turn- out by hostel

2. Voter turn -out by department

3. Voter turn- out by gender

4. Voter turn -out by academic year

\section{Bugs and error reporting}

Report blind links and any bugs you find to the developer's email address

\section{Color Codes \\ Color \\ - Red \\ - Green}

meaning

user error or invalid entry

correct/valid entry

\section{References}

[1] Kang'ethe, M Samuel, 2002, Introduction to Software Analysis and Design, Envision Publishers, Nairobi Kenya, pp. 34-40.

[2] McNurlin, C Barbara \& Sprague, H Ralph, Jnr, 2002, Information Systems Management in Practice, Pearson Education Publishers, University of Hawaii, pp. 34-40.

[3] Interim independent Electoral Commission, 2012, Interim Independent Electoral Commission, Nairobi, viewed 29th September 2004, http://www.iiebc.org.

[4] T. M. Carbaugh, "Secretary of State Kevin Shelley Announces Directives To Ensure Voter Confidence in Electronic Systems," California Secretary of State, 2003.

[5] D. L. Chaum, "Untraceable Electronic Mail, Return Addresses, and Digital Pseudonyms," Communications of 
the ACM, Vol.24, No.2, 1981, pp.84-88. http://lorrie.cranor.org/pubs/voting.html

[6] "A Better Ballot Box?" Rebecca Mercuri, IEEE Spectrum, Volume 39, Number 10,

[7] October 2002. Institute Policy Institute, "Report of the National Workshop on Internet Voting: Issues and Research Agenda," Proceedings of the 2000 Annual National Conference on Digital Government Research, 2000, pp.159 .
[8] A. M. Keller, A. Dechert, K. Auerbach, D. Mertz, A. Pearl, and J. L. Hall, "A PC-based Open-Source Voting Machine with an Accessible Voter-Verifiable Paper Ballot," Proceedings of the USENIX Annual Technical Conference, U.S.A., 2005, p.52.

[9] T. Kohno, A. Stubblefield, A. D. Ribin, and D. S. Wallach, "Analysis of an Electronic Voting System," IEEE Computer Society, 2004, pp.27-40 